\title{
Impact of exposure to insulation wool on lung function and cough in Swedish construction workers
}

\author{
M Albin, G Engholm, N Hallin, L Hagmar
}

\begin{abstract}
Objectives-To investigate whether application of insulation wool adversely affects lung volumes and increases the occurrence of symptoms of airway irritation. Methods-Data from nationwide health check ups in 1981-93 of male construction workers born in 1955 or later were used to investigate cross sectional $(n=96004)$ and longitudinal $(n=26298)$ associations between lung volumes, vital capacity (VC), and forced expiratory volume in one second $\left(\mathrm{FEV}_{1}\right)$ and exposure to insulation wool by combining a job exposure matrix (JEM) and self reported exposure. Data on 12 month prevalence of persistent cough not associated with the common cold was available for the period 1989-92. Potential confounding from smoking, exposure to asbestos, silica, and isocyanates, was considered in the analyses.
\end{abstract}

Results-For those in the highest exposure category (self reported duration of exposure of $\geqslant 11$ years, and high exposure according to the JEM) VC was on average $2.5 \mathrm{cl}$ lower $(95 \% \mathrm{CI}-6.5$ to 1.5$)$ than in those with no exposure. The corresponding figures for $\mathrm{FEV}_{1}$ was $-2.4 \mathrm{cl}(95 \% \mathrm{CI}$ -6.1 to 1.3$)$. In the longitudinal analyses, the yearly change in VC between the first and last spirometry for those in the highest exposure category was $0.50 \mathrm{cl}(95 \%$ CI -0.97 to 1.98 ) less than in the unexposed category. The corresponding figure for $\mathrm{FEV}_{1}$ was $0.89 \mathrm{cl}(95 \% \mathrm{CI}-0.70$ to 2.06$)$. High exposure to insulation wool, asbestos, or silica, during the 12 months preceding the check up was associated with increased odds ratios (ORs) for persistent cough of the same magnitude as current smoking.

Conclusions-The results indicate no effects on VC or $\mathrm{FEV}_{1}$ from exposure to insulation wool. Recent exposure to insulation wool, asbestos, and silica was associated with an increased prevalence of persistent cough.

(Occup Environ Med 1998;55:661-667)

Keywords: insulation wool; lung function; longitudinal

Correspondence to: Dr Maria Albin, Department of Occupational and Environmental Medicine, University Hospital, S-221 85 Lund, Sweden. Telephone 004646173185 ; fax 0046 46173180 ; email

Maria.Albin@ymed.lu.se

Accepted 13 May 1998

Studies of workers manufacturing insulation wool have not shown an increased morbidity from non-malignant respiratory disease, nor an impairment of lung function. ${ }^{12}$ However, exposures are higher among users than producers of insulation wool. ${ }^{34}$ An increased preva- lence of upper airway irritation ${ }^{5}$ and bronchitis ${ }^{6}$ has been found among construction workers exposed to insulation wool.

Two studies have reported decreased lung volumes among insulators and attributed this finding to exposure to insulation wool. ${ }^{78}$ Kilburn et al studied exposures to insulation wool with fine fibre diameters $(3-7 \mu \mathrm{m})$, whereas Clausen et al ${ }^{\beta}$ studied insulators in the construction industry, in which median fibre diameters of 6-15 $\mu \mathrm{m}$ (see further ${ }^{3}$ ) in bulk samples have been reported. The findings by Kilburn et $a l^{7}$ were contested with regard to the validity in the comparison with the reference population. ${ }^{9}$ The study by Clausen et $a l^{8}$ reported a remarkable effect on $\mathrm{FEV}_{1}$ from exposure to insulation wool among Danish insulators. Furthermore, obstructive lung disease (as indicated by a low forced expiratory volume in one second $\left(\mathrm{FEV}_{1}\right)$ to forced vital capacity (FVC) ratio) was found in $66 \%$. However, no associations with quantitative exposure were found, and assessment of former exposure to asbestos was only made from self reported exposure. Thus, further studies taking the mentioned methodological problems into consideration are needed.

The aim of the present study was to investigate whether application of insulation wool adversely affects lung volumes, and increases the occurrence of symptoms of airway irritation.

\section{Material and methods} SETTING

BYGGHÄLSAN, the construction industry's organisation for working environment, safety and health, was founded in 1968 on the basis of an agreement between employer organisations and labour unions concerned. It was set up to provide nationwide occupational health service to the whole Swedish construction industry. Its staff comprised medical personnel, physicians, and nurses with special training, as well as technical personnel. Regular health check ups to which workers were invited every $2-3$ years constituted the most important component of the medical programme. Attendance was voluntary and it is estimated that some $78 \%-80 \%$ of all eligible workers attended check ups during a single 2-3 year period. In the longer run as many as $85 \%-90 \%$ may have

Self reported exposure was recorded from 1984 and onwards in interviews during the check ups. For exposures to insulation wool, a least one check up. 
Table 1 Exposure according to the job exposure matrix (FEM) and self reported exposure to insulation wool, asbestos, silica, and isocyanates

\begin{tabular}{|c|c|c|c|c|c|}
\hline \multirow{3}{*}{$\begin{array}{l}\text { Self reported } \\
\text { exposure }\end{array}$} & \multicolumn{5}{|c|}{ Exposure according to the $\mathcal{F E M}(n(\%))$} \\
\hline & \multicolumn{2}{|l|}{ Own work } & \multirow[b]{2}{*}{ Bystander (2) } & \multirow[b]{2}{*}{ No exposure (3) } & \multirow[b]{2}{*}{ Unclassified (4) } \\
\hline & $\operatorname{High}(1 a)$ & Not high (1b) & & & \\
\hline \multicolumn{6}{|c|}{ Insulation wool: } \\
\hline \multicolumn{6}{|c|}{ Average daily exposure $>2 \mathrm{~h}$ in past year: } \\
\hline Yes & $2253(15.1)$ & $1090(7.3)$ & $496(9.9)$ & $83(1.4)$ & $177(4.5)$ \\
\hline No & $12669(84.9)$ & $13906(92.7)$ & $4530(90.1)$ & $5753(98.6)$ & $3792(95.5)$ \\
\hline \multicolumn{6}{|c|}{ Duration of exposure $>5 \mathrm{y}:$} \\
\hline Yes & $1154(8.2)$ & $464(3.3)$ & $317(6.7)$ & $128(2.3)$ & $56(1.5)$ \\
\hline No & $12835(91.8)$ & $13701(96.7)$ & $4410(93.3)$ & $5427(97.7)$ & $3655(98.5)$ \\
\hline \multicolumn{6}{|c|}{ Asbestos: } \\
\hline \multicolumn{6}{|c|}{ Any exposure during the past year: } \\
\hline Yes & - & $1339(9.8)$ & - & $1287(5.0)$ & $205(3.7)$ \\
\hline No & - & $12360(90.2)$ & - & $24415(95.0)$ & $5287(96.3)$ \\
\hline \multicolumn{6}{|c|}{ Duration of exposure $>5 \mathrm{y}$ : } \\
\hline Yes & - & $197(1.5)$ & - & $142(0.6)$ & $58(1.1)$ \\
\hline No & - & $12798(98.5)$ & - & $23892(99.4)$ & $5123(98.9)$ \\
\hline \multicolumn{6}{|c|}{ Silica: } \\
\hline \multicolumn{6}{|c|}{ Average daily exposure $>4 \mathrm{~h}$ in past year: } \\
\hline Yes & $582(19.6)$ & $1036(3.2)$ & $12(3.4)$ & $22(0.9)$ & $211(3.1)$ \\
\hline No & $2389(80.4)$ & $31066(96.8)$ & $341(96.6)$ & $2542(99.1)$ & $6657(96.9)$ \\
\hline \multicolumn{6}{|c|}{ Duration of exposure $>5 \mathrm{y}$ : } \\
\hline Yes & $323(11.6)$ & $836(2.8)$ & $10(3.0)$ & $30(1.2)$ & $146(2.2)$ \\
\hline No & $2463(88.4)$ & $29524(97.2)$ & $322(97.0)$ & $2403(98.2)$ & $6382(97.8)$ \\
\hline \multicolumn{6}{|c|}{ Isocyanates: } \\
\hline \multicolumn{6}{|c|}{ Any exposure during the last year: } \\
\hline Yes & - & $3833(21.4)$ & - & $989(4.9)$ & $405(5.9)$ \\
\hline No & - & $14062(78.6)$ & - & $19209(95.1)$ & $6476(94.1)$ \\
\hline
\end{tabular}

Information was not available as to whether the workers had a self reported duration of exposure to isocyanates of $>5 \mathrm{y}$ or not.

silica dust, asbestos, and isocyanates the first and the last year of exposure was recorded, as well as the total duration of exposure (number of 8 hour shifts) during the 12 months before the check up.

Starting in 1989, self reported exposure was also registered from a self administered questionnaire that considered exposures as well as symptoms. The exposure questions considered whether the subject had been exposed for $>5$ years or not, and whether he had during the 12 months preceding the check up on average been exposed to insulation wool for $>2$ hours a day, or not (for other agents, see table 1 ).

JOB CODES AND THE JOB EXPOSURE MATRIX During the check up the interviewing nurse assigned appropriate occupation codes to the examinee. These codes were chosen from a list of specific tasks in the industry. Occupation codes constitute links to a job exposure matrix (JEM) developed by BYGGHÄLSAN hygienists. The JEM specifies on an ordinal scale the average level of exposure to insulation wool, asbestos, silica, and isocyanates respectively for

Table 2 fob exposure matrix for the 11 occupations with own work with insulation wool

\begin{tabular}{llllll}
\hline Occupation & $\begin{array}{l}\text { Insulation } \\
\text { wool }\end{array}$ & Asbestos & Silica & Isocyanates & $\begin{array}{l}\text { fob stability } \\
\text { (\%) }\end{array}$ \\
\hline Insulators & $1 \mathrm{a}$ & $1 \mathrm{~b}$ & 2 & $1 \mathrm{~b}^{\star}$ & 79.4 \\
Carpenters & $1 \mathrm{a}$ & 3 & $1 \mathrm{~b}$ & $1 \mathrm{~b}$ & 91.3 \\
Plumbers & $1 \mathrm{a}$ & $1 \mathrm{~b}$ & $1 \mathrm{~b}$ & $1 \mathrm{~b}^{\star}$ & 93.1 \\
Concrete workers & $1 \mathrm{~b}$ & 3 & $1 \mathrm{a}$ & 3 & 72.4 \\
Refrigeration mechanics & $1 \mathrm{~b}$ & $1 \mathrm{~b}$ & 3 & $1 \mathrm{~b}$ & 90.0 \\
Brick layers & $1 \mathrm{~b}$ & 3 & $1 \mathrm{~b}$ & $1 \mathrm{~b}$ & 83.4 \\
Electricians & $1 \mathrm{~b}$ & $1 \mathrm{~b}$ & $1 \mathrm{~b}$ & $1 \mathrm{~b}$ & 94.3 \\
Repairmen & $1 \mathrm{~b}$ & 4 & 4 & 4 & 69.8 \\
Ground preparers & $1 \mathrm{~b}^{\star}$ & 3 & $1 \mathrm{~b}$ & 3 & 69.0 \\
Roofers & $1 \mathrm{~b}^{\star}$ & $1 \mathrm{~b}$ & 3 & 3 & 75.4 \\
Sheet metal workers & $1 \mathrm{~b}^{\star}$ & $1 \mathrm{~b}$ & $1 \mathrm{~b}$ & 3 & 90.6 \\
\hline
\end{tabular}

*Only a small proportion of subjects in the occupation are exposed.

Exposure classification: $1=$ occupation includes own work with the material $(1 \mathrm{a}=$ high exposure, $1 \mathrm{~b}=$ others), $2=$ no personal work with the material, but exposure might occur through the work of other trades (bystander exposure), $3=$ no exposure, $4=$ unclassified. Job stability=proportion of subjects having the same occupational code at the first and second health check up. the various job categories. In the development of the JEM the hygienist based his classification on decade long experience of the industry but also on measurements carried out. Jobs which involve handling insulation wool either with heavy exposure or other exposure are listed in table 2. The table also specifies for each job category the proportion of workers remaining in the same category at a second check up.

MONITORING OF DUST CONCENTRATIONS

Airborne fibre and dust concentrations at the construction sites, have been monitored, with personal sampling, by the Hygiene Department of BYGGHÄLSAN. Measured respirable fibre concentrations in air at different work sites 1978-90 where insulation wool was handled are shown in table 3. The distributions were skewed. The median concentrations of respirable fibres were between 0.06 and 0.50 $\mathrm{f} / \mathrm{ml}$ (75th percentile $0.06-0.70 \mathrm{f} / \mathrm{ml}$ ). Total dust concentrations were measured only until the end of 1985. The median concentrations were $0.85-3.15 \mathrm{mg} / \mathrm{m}^{3} \quad$ (75th percentiles $\left.0.9-13 \mathrm{mg} / \mathrm{m}^{3}\right)$. A notation that a personal respiratory protection device was used, was made only for four measurements, three of them with total dust concentrations $\geqslant 10 \mathrm{mg} / \mathrm{m}^{3}$.

\section{SCALES OF EXPOSURE}

Scales of exposure were based on the JEM and on self reported exposure. In analyses of lung capacity relative to exposure the scale was based on the JEM and duration of exposure. Cross tabulations between the JEM and self reported exposure obtained through the 1989 self administered questionnaire are shown in table 1 . The distributions indicate that substantial misclassification may be introduced by considering only the JEM or self reported exposure in the exposure assessment. Thus, we 
Table 3 Respirable fibre and total dust concentrations in air 1978-90 for different occupations within the construction industry

\begin{tabular}{|c|c|c|c|c|c|c|}
\hline \multirow[b]{2}{*}{ Occupation (comment) } & \multirow[b]{2}{*}{ Samples (n) } & \multirow{2}{*}{$\begin{array}{l}\text { Sampling time } \\
\text { Mean (h) }\end{array}$} & \multicolumn{4}{|l|}{ Concentration } \\
\hline & & & Mean (range) & Q25 & Median & Q75 \\
\hline \multicolumn{7}{|c|}{$\begin{array}{l}\text { Insulators (specialised workers doing similar tasks at different construction sites): } \\
\text { Spraying insulation wool: }\end{array}$} \\
\hline Respirable fibres $(\mathrm{f} / \mathrm{ml})$ & 18 & 4.17 & $0.91(0.08-5.08)$ & 0.13 & 0.42 & 0.63 \\
\hline Total dust $\left(\mathrm{mg} / \mathrm{m}^{3}\right)$ & 4 & & $7.42(1.70-21.70)$ & 1.95 & 3.15 & 12.90 \\
\hline \multicolumn{7}{|c|}{ Spraying mixed gypsum and insulation wool: } \\
\hline Respirable fibres $(\mathrm{f} / \mathrm{ml})$ & 5 & 4.84 & $0.42(0.19-0.74)$ & 0.19 & 0.34 & 0.74 \\
\hline Total dust $\left(\mathrm{mg} / \mathrm{m}^{3}\right)$ & 5 & & $11.10(1.25-39.26)$ & 1.50 & 2.70 & 10.8 \\
\hline \multicolumn{7}{|c|}{ Manual application of mattresses etc: } \\
\hline Respirable fibres (f/ml) & 57 & 3.01 & $0.18(0.00-1.41)$ & 0.04 & 0.10 & 0.21 \\
\hline Total dust $\left(\mathrm{mg} / \mathrm{m}^{3}\right)$ & 24 & & $2.42(0.80-9.05)$ & 1.17 & 1.70 & 2.93 \\
\hline \multicolumn{7}{|c|}{ Carpenters: } \\
\hline \multicolumn{7}{|c|}{ Work tasks performed several days/week: } \\
\hline Respirable fibres (f/ml) & 36 & 1.95 & $0.36(0.07-1.90)$ & 0.12 & 0.22 & 0.35 \\
\hline Total dust $\left(\mathrm{mg} / \mathrm{m}^{3}\right)$ & 4 & & $1.52(0.75-2.22)$ & 1.00 & 1.56 & 2.04 \\
\hline \multicolumn{7}{|l|}{ As above, but may be rarer: } \\
\hline Respirable fibres (f/ml) & 1 & 3.70 & $0.33(0.33-0.33)$ & 0.33 & 0.33 & 0.33 \\
\hline Total dust $\left(\mathrm{mg} / \mathrm{m}^{3}\right)$ & 0 & & & & & \\
\hline \multicolumn{7}{|c|}{ As above, but may be daily for weeks: } \\
\hline Respirable fibres $(\mathrm{f} / \mathrm{ml})$ & 3 & 1.03 & $0.12(0.02-0.20)$ & 0.02 & 0.13 & 0.20 \\
\hline \multirow{2}{*}{\multicolumn{7}{|c|}{ Specialised workers doing similar tasks at different construction sites, spraying insulation wool: }} \\
\hline & & & & & & \\
\hline Respirable fibres (f/ml) & 5 & 3.63 & $0.14(0.10-0.20)$ & 0.11 & 0.11 & 0.19 \\
\hline Total dust $\left(\mathrm{mg} / \mathrm{m}^{3}\right)$ & 5 & & $0.89(0.30-1.70)$ & 0.45 & 0.98 & 1.00 \\
\hline \multicolumn{7}{|l|}{ Sheet metal workers: } \\
\hline \multicolumn{7}{|c|}{ Varying frequency, subspecialisation occurs: } \\
\hline Respirable fibres (f/ml) & 1 & 4.30 & $0.06(0.06-0.06)$ & 0.06 & 0.06 & 0.06 \\
\hline Total dust $\left(\mathrm{mg} / \mathrm{m}^{3}\right)$ & 1 & & $0.85(0.85-0.85)$ & 0.85 & 0.85 & 0.85 \\
\hline \multicolumn{7}{|c|}{ Painters: } \\
\hline \multicolumn{7}{|c|}{ Varying frequency, subspecialisation occurs: } \\
\hline Respirable fibres (f/ml) & 4 & 6.60 & $0.47(0.19-0.71)$ & 0.25 & 0.50 & 0.70 \\
\hline Total dust $\left(\mathrm{mg} / \mathrm{m}^{3}\right)$ & 3 & & $4.19(3.81-4.77)$ & 3.81 & 4.00 & 4.77 \\
\hline
\end{tabular}

All samples were obtained by personal monitoring in the breathing zone. Two samples from spraying of insulation wool, and two samples from spraying a mixture of insulation wool and gypsum have a notation that a personal respiratory protection device was used. Comments refer to the respresentativity of the sample for the exposure of that specific occupation. (Measurements performed $1979-80$ have been reported previously. ${ }^{12}$ )

chose to combine the information by cross classification.

STUDY POPULATIONS

The study base was chosen to minimise the risk that it would comprise subjects with substantial exposure to asbestos. Asbestos use in the Swedish construction industry was markedly reduced in 1975. Accordingly, only subjects born in 1955 or later were included. Female construction workers were excluded because they were too few. The number of male workers meeting the selection criteria was 110546 . Spirometry data had been registered on computer files since July 1978. The number of subjects with at least one recorded spirometry was 96963 . Further data on the different study populations are given in table 4 . Subjects with at least two spirometries did not differ in mean $\mathrm{VC}$ or $\mathrm{FEV}_{1}$, at the first examination from those with only one spirometry (mean difference around $0.1 \%$ ). However, a slightly higher proportion were current smokers among those with more than one spirometry than among those with only one examination (30\% v 27\%). Moreover, a higher proportion of those with more than one spirometry than of those with only one examination had, according to the

Table 4 The different study populations

\begin{tabular}{lc}
\hline & $n$ \\
\hline Total study base & 110546 \\
Study bases available for cross sectional analyses: & \\
$\geqslant 1$ Spirometry (1981-93) and height & 96004 \\
$\geqslant 1$ Spirometry (1984-93), height and self reported exposure & 83993 \\
Subjects with data on symptoms (1989-92), JEM, and self reported exposure & 45716 \\
Study bases available for longitudinal analyses: & 26298 \\
$\quad \geqslant 2$ Spirometries (1981-93) and height & 20086 \\
$\geqslant 2$ Spirometries (1984-93), height, and self reported exposure & \\
\hline
\end{tabular}

JEM, had high exposure at the first examination $(43 \% v 34 \%$, for ages $18-27$ at first examination).

SMOKING DATA

Smoking became increasingly rare during the study period and was also rarer in the youngest subjects. The proportion of current smokers varied from $17 \%$ in subjects $<20$ years of age in 1989 and later, to $>35 \%$ in subjects $\geqslant 20$ years of age in 1978-82.

\section{SPIROMETRY}

According to the routines, all workers should undergo at least one spirometric examination. Furthermore, an additional examination should take place whenever a worker met certain exposure criteria. The proportion of all health check ups involving spirometry varied between $82 \%$ and $92 \%$ for the different geographical regions during the period 1978-92. During the first 6 months of 1981, however, a major effort was made and spirometric examination was part of all check ups.

The investigators were encouraged to note if they were unsatisfied with the quality of the examination. A minimum of three approved registrations of $\mathrm{VC}$ and $\mathrm{FEV}_{1}$ were required, which were not allowed to differ by $>10 \%$ of the lowest value. The best approved registrations of $\mathrm{VC}$ and $\mathrm{FEV}_{1}$ were reported to the data base, together with information on height, weight, and smoking habits.

Before the campaign in 1981 was launched, all staff obtained special training to calibrate the equipment and carry out the examination. Data collected during the first 6 months of 1981 for some 26000 subjects free from respiratory diseases formed the basis for calculation of age, 


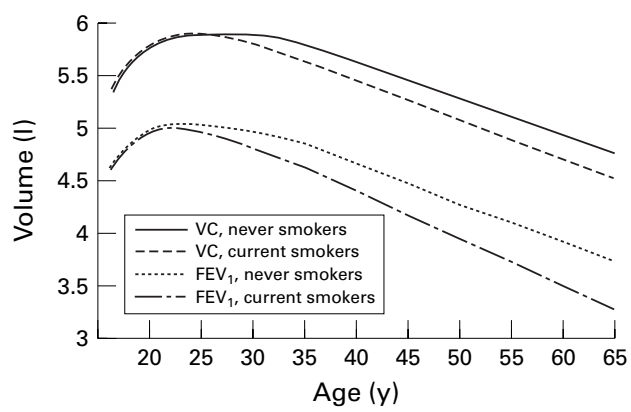

Figure 1 Reference values for $\mathrm{VC}$ and $\mathrm{FEV} V_{1}$ by age, for never smokers, former smokers, and current smokers, shown for men with a height of $180 \mathrm{~cm}$.

height, and smoking category specific reference values for $\mathrm{VC}$ and $\mathrm{FEV}_{1}$. Smoking category and age specific reference values for subjects with height $180 \mathrm{~cm}$ are shown in figure 1.

SYMPTOMS

The answers to a question about persistent cough during the past 12 months not associated with common cold with the fixed alternative answers: never, rarely, sometimes, often, or very often, were systematically collected at the health check ups and registered in the data base but only for the period 1989-92.

STATISTICS

In the analyses of spirometry data, the volume indices, $\mathrm{VC}$ and $\mathrm{FEV}_{1}$ have been related to age, height, and smoking category specific reference values. For instance, in cross sectional analysis VC has been expressed as a standardised value according to the following:

$$
V C_{\text {Standard }}=100 \times V C_{\text {Observed }} / V C_{\text {Reference }}
$$

The cross sectional analyses were only based on data recorded at the first check up of each subject concerned. This means that the exposure category classification was based on the first recorded duration of exposure and JEM data corresponding to the first recorded occupational code. Comparisons between categories were made by multiple linear regression analyses in which indicators for all exposure levels except the no exposure level were used as regressors. Such analyses were carried out only with indicators of exposure to insulation wool in the model but also with indicators of other exposures in the model.

Spirometry data from more than two check ups are available for only a very few subjects. Longitudinal analyses therefore only use data from the first and last check up of those with more than one check up. Exposure classification is based on recorded duration of exposure and JEM data corresponding to recordings of occupational codes at both check ups. The variable studied in each subject is his annual change of the deviation from reference values. The measure describing the annual change is given by the equation:

\section{$\frac{[V C(2)-\operatorname{Ref} V C(2)])-[V C(1)-\operatorname{RefVC}(1)]}{t}$}

where $V C(1)$ and $V C(2)$ are the observed VC values at the first and the last check up respectively and $\operatorname{RefVC}(1)$ and $\operatorname{RefVC}(2)$ are the corresponding reference values; and t years is the time distance between the check ups. Initial controls of the available data concerned height, weight, body mass index, and data on smoking and spirometry from each check up. For subjects with more than one check up, changes between check ups were also studied. These controls showed only a few inconsistencies. For subjects with values that seemed unreasonable, the data were marked as such. Analyses were made with and without inclusion of such data, and in general it made no difference whether or not the data were included.

To decrease the misclassification bias, subjects who stated that they rarely had persistent cough were excluded from analysis of this symptom. The others have been divided into the categories never versus sometimes, or often, or very often. Analysis was carried by logistic regression in which indicators of the various levels of exposure were regressors.

\section{Results}

LUNG VOLUMES RELATIVE TO EXPOSURE

Cross sectional analyses

For duration of exposure combined with the JEM (table 5), no associations were found

Table 5 Cross sectional analysis: differences in lung volumes for different categories of exposure to insulation wool, as cross classified according to self reported duration of exposure and exposure level according to a job exposure matrix (FEM)

\begin{tabular}{|c|c|c|c|c|}
\hline $\mathcal{F E M}$ & $\begin{array}{l}\text { Self reported } \\
\text { exposure }(y)\end{array}$ & $n$ & $\begin{array}{l}\text { VC difference (cl) } \\
\text { Mean }^{\star}(95 \% \text { CI })\end{array}$ & $\begin{array}{l}F E V_{1} \text { difference }(\mathrm{cl}) \\
\text { Mean }^{*}(95 \% \mathrm{CI})\end{array}$ \\
\hline \multicolumn{5}{|c|}{ Bivariate model (insulation wool and smoking): } \\
\hline \multirow[t]{2}{*}{ Own work, high (1a) } & $\geqslant 11$ & 1026 & $-1.0(-4.9$ to 2.9$)$ & $-1.4(-5.0$ to 2.2$)$ \\
\hline & $1-10$ & 2360 & $3.5(0.8$ to 6.3$)$ & $2.7(0.2$ to 5.3$)$ \\
\hline \multirow[t]{2}{*}{ Own work, not high (1b) } & $\geqslant 11$ & 345 & $6.3(-0.2$ to 12.7$)$ & $3.7(-2.3$ to 9.6$)$ \\
\hline & $1-10$ & 1040 & $3.4(-0.4$ to 7.3$)$ & $3.9(0.4$ to 7.5$)$ \\
\hline Other combinations & & 67633 & $2.7(1.3$ to 4.1$)$ & $1.7(0.4$ to 3.0$)$ \\
\hline No exposure & No exposure & 7758 & Reference & Reference \\
\hline \multicolumn{5}{|l|}{ Full model: } \\
\hline \multirow[t]{2}{*}{ Own work, high (1a) } & $\geqslant 11$ & 1026 & $-2.5(-6.5$ to 1.5$)$ & $-2.4(-6.1$ to 1.3$)$ \\
\hline & $1-10$ & 2360 & $1.9(-1.0$ to 4.7$)$ & $1.4(-1.2$ to 4.0$)$ \\
\hline \multirow[t]{2}{*}{ Own work, not high (1b) } & $\geqslant 11$ & 345 & $7.0(0.4$ to 13.5$)$ & $4.2(-1.8$ to 10.3$)$ \\
\hline & $1-10$ & 1040 & $3.6(-0.4$ to 7.5$)$ & $3.4(-0.3$ to 7.0$)$ \\
\hline Other combinations & & 67633 & $2.5(1.0$ to 4.0$)$ & $1.3(-0.1$ to 2.7$)$ \\
\hline No exposure & No exposure & 7758 & Reference & Reference \\
\hline
\end{tabular}

*Arithmetic mean.

Cross classified exposures to insulation wool, asbestos, silica, and isocyanates, and smoking category, were considered simultaneously in the full multiple regression model. Expected values were smoking category specific. Smoking category was still included in the model to account for residual confounding. No consistent effects were found from exposure to silica, asbestos, or isocyanates. 
Table 6 Longitudinal analysis: yearly change in lung volumes for different categories of exposure to insulation wool, as cross classified according to self reported duration of exposure and exposure level according to a job exposure matrix ( $(F E M)$ at the last check up

\begin{tabular}{|c|c|c|c|c|}
\hline$f E M$ & $\begin{array}{l}\text { Self reported } \\
\text { exposure }(y)\end{array}$ & $n$ & $\begin{array}{l}\text { VC difference (cl) } \\
\text { Mean }^{\star}(95 \% \text { CI })\end{array}$ & $\begin{array}{l}F E V_{1} \text { difference }(\mathrm{cl}) \\
\text { Mean }^{\star}(95 \% \mathrm{CI})\end{array}$ \\
\hline \multicolumn{5}{|c|}{ Bivariate model (insulation wool and smoking): } \\
\hline \multirow[t]{2}{*}{ Own work, high (1a) } & $\geqslant 11$ & 414 & $0.80(-0.62$ to 2.23$)$ & $0.89(-0.45$ to 2.22$)$ \\
\hline & $1-10$ & 677 & $-0.50(-1.68$ to 0.68$)$ & $0.17(-0.94$ to 1.27$)$ \\
\hline \multirow[t]{2}{*}{ Own work, not high (1b) } & $\geqslant 11$ & 134 & $-0.18(-2.52$ to 2.15$)$ & $-0.46(-2.64$ to 1.73$)$ \\
\hline & $1-10$ & 306 & $0.88(-0.74$ to 2.49$)$ & $0.85(-0.66$ to 2.36$)$ \\
\hline Other combinations & & 15181 & $0.10(-0.57$ to 0.77$)$ & $1.00(-0.50$ to 0.73$)$ \\
\hline No exposure & No exposure & 1724 & Reference & Reference \\
\hline \multicolumn{5}{|l|}{ Full model: } \\
\hline \multirow{2}{*}{ Own work, high (1a) } & $\geqslant 11$ & 414 & $0.50(-0.97$ to 1.98$)$ & $0.68(-0.70$ to 2.06$)$ \\
\hline & $1-10$ & 677 & $-0.73(-1.95$ to 0.50$)$ & $0.05(-1.10$ to 1.20$)$ \\
\hline \multirow[t]{2}{*}{ Own work, not high (1b) } & $\geqslant 11$ & 134 & $-0.23(-2.6$ to 2.15$)$ & $-0.58(-2.80$ to 1.65$)$ \\
\hline & $1-10$ & 306 & $1.09(-0.55$ to 2.74$)$ & $1.09(-0.45$ to 2.63$)$ \\
\hline Other combinations & & 15181 & $-0.01(-0.71$ to 0.69$)$ & $0.11(-0.55$ to 0.76$)$ \\
\hline No exposure & No exposure & 1724 & Reference & Reference \\
\hline
\end{tabular}

^Arithmetic mean.

Cross classified exposures to insulation wool, asbestos, silica, and isocyanates, and smoking category, were considered simultaneously in the full multiple regression model. Expected values were specific to smoking category. Smoking category was still included in the model to account for residual confounding. No consistent effects were found from exposure to silica, asbestos, or isocyanates. Negative values indicate a faster decline in lung volumes than in the reference category.

Table 7 Odds ratios (OR) (95\% CIs) for persistent cough for exposures to insulation wool, silica, and asbestos, as cross classified from a job exposure matrix, and self reported average exposure during the past year

\begin{tabular}{|c|c|c|c|c|}
\hline fob exposure matrix & $\begin{array}{l}\text { Self reported } \\
\text { exposure ( } h / \text { day) }\end{array}$ & $n$ & $\begin{array}{l}\text { Bivariate model OR } \\
(95 \% C I)\end{array}$ & Full model OR $(95 \%$ CI) \\
\hline \multicolumn{5}{|l|}{ Insulation wool: } \\
\hline Own work, high & $>2$ & 1747 & $2.74(2.33$ to 3.22$)$ & $2.59(2.19$ to 3.06$)$ \\
\hline Own work, not high & $>2$ & 858 & $2.84(2.33$ to 3.46$)$ & $2.41(1.96$ to 2.96$)$ \\
\hline Other combinations & Other & 29483 & $1.36(1.21$ to 1.53$)$ & $1.31(1.15$ to 1.48$)$ \\
\hline None & $\leqslant 2$ & 4280 & Reference & Reference \\
\hline \multicolumn{5}{|l|}{ Silica: } \\
\hline Own work, high & $>4$ & 460 & & $2.31(1.74$ to 3.07$)$ \\
\hline Own work, not high & $>4$ & 805 & & $1.57(1.22$ to 2.03$)$ \\
\hline Other combinations & Other & 33488 & & $1.02(0.85$ to 1.22$)$ \\
\hline None & $\leqslant 4$ & 1615 & & Reference \\
\hline \multicolumn{5}{|l|}{ Asbestos: } \\
\hline Own work, not high & Any exposure & 1069 & & $1.80(1.53$ to 2.12$)$ \\
\hline Other combinations & Other & 15184 & & $1.06(0.99$ to 1.14$)$ \\
\hline None & No exposure & 20115 & & Reference \\
\hline \multicolumn{5}{|l|}{ Smoking: } \\
\hline Current smoker & & 7264 & $2.63(2.45$ to 2.83$)$ & $2.61(2.43$ to 2.81$)$ \\
\hline Former smoker & & 4137 & $1.16(1.04$ to 1.30$)$ & 1.15 (1.03 to 1.28$)$ \\
\hline Never smoker & & 24967 & Reference & Reference \\
\hline
\end{tabular}

For exposure to asbestos, no occupation was classified as own work, high exposure in the JEM.

All exposures, and smoking category, were considered simultaneously in the full multiple logistic regression model.

between high exposure and low lung volumes. The same applied to exposures during the past year combined with the JEM. Moreover, no new information was obtained when duration of exposure and exposure during the past year, was combined with the JEM.

Odds ratios (ORs) for low $(<85 \%$ of expected) volumes did not increase with increasing exposure category for insulation wool (all other exposures included in the model), including combinations of duration of exposure and exposure during the past year with the JEM (OR for low VC for high exposure, $\geqslant 11$ years, $\geqslant 50$ days $=1.13,95 \%$ CI 0.86 to 1.49 ).

\section{Longitudinal analyses}

Longitudinal data were cross classified in a similar way, and the exposure criteria were sharpened by demanding high exposure according to the JEM both at the first and the second check up. The mean (SD) time between the first and the last check up was 3.9 (1.6) years. The estimates of the annual changes were now slightly, but not significantly, less than expected for both VC and $\mathrm{FEV}_{1}$ in the highest exposure compared with the unexposed category (table 6).
EXPOSURE AND PERSISTENT COUGH

Exposures according to the JEM and self reported exposures during the past year to insulation wool, silica, and asbestos were cross classified (table 7). Dose-response relations for all three agents were indicated in univariate analyses for both sets of exposure scales, and confirmed in multiple logistic regression analyses. The odds ratios for persistent cough were similar for high exposure to insulation wool (OR 2.59, 95\% CI 2.19 to 3.06) and current smoking (OR 2.61, 95\% CI 2.43 to 2.81 ).

INTERACTION BETWEEN LUNG VOLUMES, PERSISTENT COUGH, AND EXPOSURE

Negative associations were found, as expected, between the prevalence of persistent cough and mainly $\mathrm{FEV}_{1}$, but also VC. Stratification by the prevalence of persistent cough showed in univariate analyses no clear effects of exposure to insulation wool, according to the JEM, on $\mathrm{VC}$ or $\mathrm{FEV}_{1}$, neither for self reported exposure during the past year (fig 2), nor for years of exposure.

In multivariate regression analyses, simultaneously including prevalence of persistent cough and exposures to asbestos, silica, and insulation wool according to the JEM, a clear 

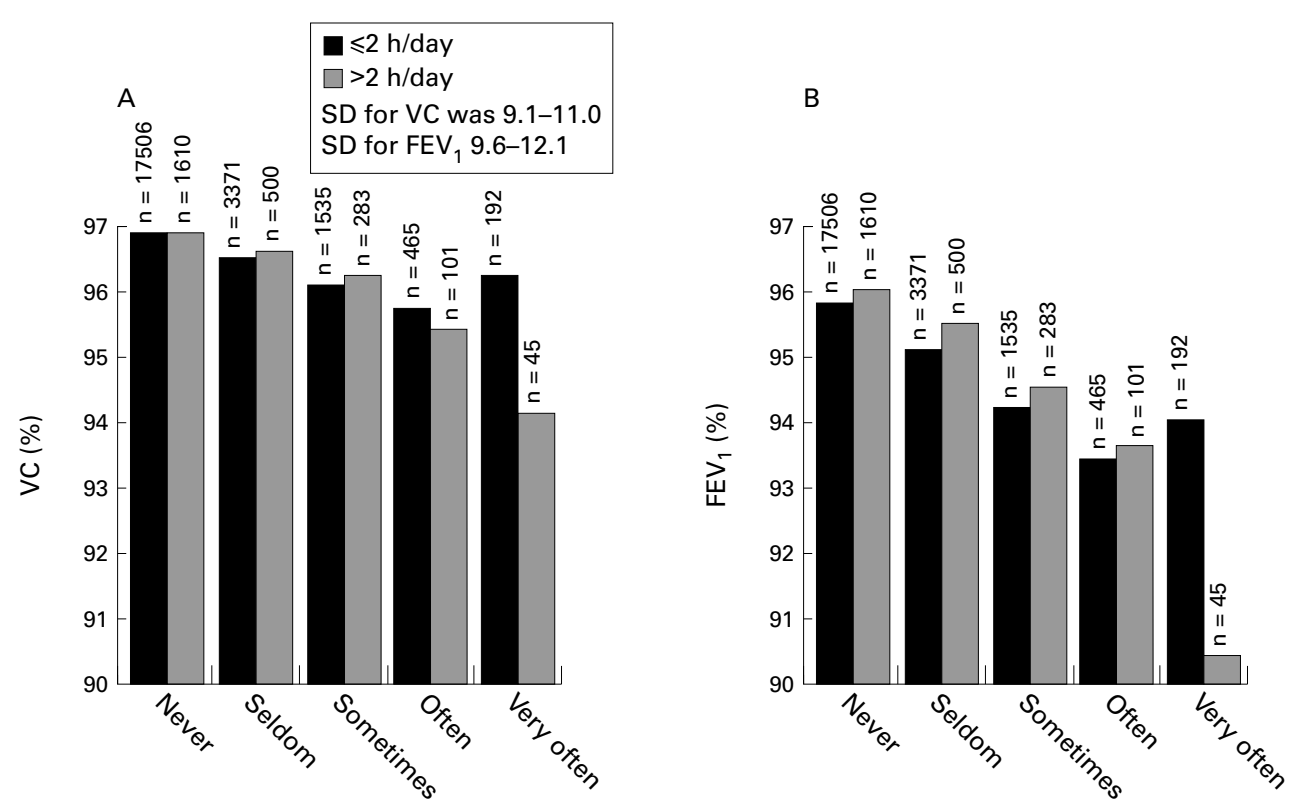

Figure $2 \quad V C$ and $F E V_{l}$ (\% of expected) by prevalence of persistent cough and self reported average daily exposure to insulation wool during the past year.

effect of prevalence of cough was still found on the lung volumes, but no effect of exposure to insulation wool was found. The same pattern was found for self reported exposure to insulation wool during the past year, and number of years of exposure.

\section{Discussion}

This study is negative for effects on lung function from exposure to insulation wool. It is likely that both the JEM and self reported exposures, as indicated by table 1 , include substantial misclassification, which tends to dilute potential dose-response relations. We handled this problem by creating a scale of exposure based on a combination of JEM and self reported exposures, which we think allowed a more valid contrast between high exposure and no exposure. Our choice to study fairly young subjects to avoid effects of asbestos exposure, limited the chance to study effects of longer exposure durations than about 15 years.

We have no reason to assume that workers covered by the health check ups are nonrepresentative for exposure conditions in the construction industry. Virtually all construction workers were affiliated to the health service. Construction work is generally physically demanding, irrespective of whether associated with dust exposure or not. However, it is possible that subjects with respiratory symptoms or a family history of asthma, less often go into insulation work. This would introduce a bias in the cross sectional analyses, but it is likely that an effect of exposure to insulation wool on lung function would have been detected in the longitudinal analyses.

The annual decline found in the longitudinal analyses was generally lower than expected from the cross sectional data (VC $3.3 \mathrm{cl}, \mathrm{FEV}_{1}$ $3.6 \mathrm{cl}$, not in results). This is in accordance with previous findings, ${ }^{11}$ but may also indicate a selection out of construction work, associated with lung volumes. This selection would intro- duce a negative bias in the longitudinal analyses if it was also associated with high exposure to dust. We did, however, not find any obvious gradient in the turnover of the work force associated with dust exposure as estimated from the JEM (table 2). Further, subjects with more than one spirometry had a higher prevalence of high exposure at the first examination than those with only one spirometry.

Methodological instructions were clear for the spirometric investigations. In 1981 special efforts were made to obtain a high quality. Separate cross sectional analyses including data only from this year (not in results) give the same relations between exposure categories as data collected after 1981. However, decreasing trends in VC and $\mathrm{FEV}_{1}$ were found with calendar year of examination. We have at present no explanation for this, but these trends do not confound the estimated effects of exposure.

Thus, our results do not indicate that exposure to insulation wool as experienced by construction workers born in 1955 or later, has significantly affected VC or $\mathrm{FEV}_{1}$. This contrasts with what was presented for Danish insulators by Clausen et al. ${ }^{8}$ Their typical exposure conditions were, as estimated from personal sampling, $0.03-1 \mathrm{f} / \mathrm{ml}$, which is close to the mean values for the Swedish insulators $1978-90(0.2-0.9 \mathrm{f} / \mathrm{ml})$. The range of total airborne dust concentrations was also similar (1-10 $\mathrm{mg} / \mathrm{m}^{3}$ and $2-11 \mathrm{mg} / \mathrm{m}^{3}$, respectively). We have thus no reason to assume that differences in exposure intensities explain the discrepancies between the findings in the two studies.

We restricted our study to workers born in or after 1955 (median age 22 years) to minimise residual confounding of asbestos exposure, and the mean follow up time in the longitudinal study was 4 years, whereas the workers in the Danish study had a mean age of 42 years, but a similar follow up time of 6 years. It may be 
argued that a substantial duration of exposure is required, before a significant adverse effect on lung function occurs. To elucidate this we examined lung function separately in strata with at least 11 years duration of exposure to insulation wool, and found a reduction in VC and $\mathrm{FEV}_{1}$ of $0.5 \%$. A sharpening of the exposure criteria to reduce dilution of potential effects did not increase these estimates. Clausen $e t a l^{8}$ found in a cross sectional analysis of workers with a mean exposure duration of 14 years, an $\mathrm{FEV}_{1}$ which was on average 0.91 $(27 \%)$ less than among the referents. They further found an annual decline in FVC which was on average twice as high in insulators (7.7 $\mathrm{cl})$ as in controls $(3.1 \mathrm{cl})$, and a fivefold increase in the annual decline of $\mathrm{FEV}_{1}(17.0 \vee 2.9 \mathrm{cl})$. By contrast with these findings, our $95 \%$ CIs for the estimate of the annual decline in VC and $\mathrm{FEV}_{1}$ for high exposure to insulation wool exclude an annual change exceeding that in the unexposed group with $>1 \mathrm{cl}$. Our estimated annual decline for insulators was only $0.13 \mathrm{cl}$ for $\mathrm{VC}$ and $1.7 \mathrm{cl}$ for $\mathrm{FEV}_{1}$ (not in results). Thus, we consider it extremely unlikely that effects of the magnitude found by Clausen $e t a l^{8}$ could be present in our material.

However, strong associations were found between exposure to insulation wool, silica, and asbestos, and the non-specific symptom persistent cough during the past 12 months without a common cold. Clear dose-response associations were found for all three types of dust when exposure was cross classified according to the JEM and self reported exposure. This was found both for exposure during the past 12 months and duration of exposure, which is consistent with a nonspecific irritation effect. For those with high exposure from handling insulation wool (according to the JEM), and a self reported exposure $>2$ hours/day during the past 12 months, the OR for persistent cough was just as high as for current smokers. This is in accordance with results of Engholm and von Schmalensee, ${ }^{6}$ who found that bronchitis, defined as presence of cough and sputum for three months of a year, was 1.5-2.7 times more prevalent in different smoking categories of construction workers with at least 3 years of exposure to insulation wool than with unexposed workers. Further, Petersen and Sabroe ${ }^{5}$ reported that cough during the day was two to three times more prevalent among insulation workers reporting full time exposure to mineral wool during the past year than among construction workers with no exposure to mineral wool.
The similarity in effect for persistent cough between silica, asbestos, and insulation wool in our material, seems to suggest that the cough is caused by a non-specific irritation from these dusts. Such irritation may be limited to the upper respiratory tract, or include an inflammatory response in the lower airways associated with an increased sensory bronchial responsiveness, with or without bronchoconstriction or asthma. Associations in this study between persistent cough and lower lung volumes indicate that persistent cough is associated with chronic obstruction of the airways. However, our analyses do not indicate that this association was mediated through exposure to insulation wool.

As our data, together with two former studies, consistently indicate that exposure to insulation wool is associated with airways irritation, it is prudent to investigate whether it is also associated with an increased risk of asthma.

This study was supported by funds from the Swedish Council for Work Life Research (grant 95-0358), and from the Medical Faculty, Lund University. The material was made available to us by the Steering Group for Data Collected by BYGGHÄLSAN. This is gratefully acknowledged.

1 Chiazze L, Watkins DK, Fryar C, et al. A case-control study of malignant and non-malignant respiratory disease among employees of a fibreglass manufacturing facility. II Exposure assessment. BrF Ind Med 1993;50:717-25.

2 Hughes JM, Jones RN, Glindmeyer HW, et al. Follow up study of workers exposed to man made mineral fibres. $B r f$ Ind Med 1993;50:658-67.

3 International Agency for Research on Cancer. Man-made mineral fibres and radon. IARC monographs on the evaluation of carcinogenic risks to humans. Vol 43. Lyon: IARC, 1988.

4 Yeung P, Rogers A, Baker E. Australian exposure databank on synthetic mineral fibres (glasswool and rockwool) in 1991-2. Final report prepared for Insulation Wools Research Advisory Board. Sidney: Occupational Hygiene and Safety Engineering Unit, Research Science and Statistics Division, Worksafe Australia, December 1994.

Worksafe Australia, December 1994 .
5 Petersen R, Sabroe S. Irritative symptoms and exposure to mineral wool. Am F Ind Med 1991;20:113-22.

6 Engholm G, von Schmalensee G. Bronchitis and exposure to man-made mineral fibers in non-smoking construction workers. Eur f Respir Dis 1982;63:73-8.

7 Kilburn KH, Powers D, Warshaw RH. Pulmonary effects of exposure to fine fibre-glass: irregular opacities and small exposure to fine fibre-glass: irregular opacities and

8 Clausen J, Netterström B, Wolff C. Lung function in insulation workers. Br F Ind Med 1993;50:252-6.

9 Rossiter CE. Pulmonary effects of exposure to fine fibreglass: irregular opacities and small airways obstruction. Br F Ind Med 1993;50:382-3.

10 Engholm G, Englund A. Morbidity and mortality patterns in Sweden. Occup Med 1995;10:261-8.

11 Burrows B, Lebowitz MD, Camilli AE, et al. Longitudinal changes in forced expiratory volume in adults. Methodochanges in forced expiratory volume in adults. MethodoAm Rev Respir Dis 1986;133;974-80.

12 Hallin N. Mineral wool dust in construction sites. Stockholm: BYGGHÄLSAN, The Construction Industry's Organization for Working Environment Safety and Health, 1981. (Report 1981-09-01.) 